\title{
Liver Kinase B1/AMP-Activated Protein Kinase Pathway Activation Attenuated the Progression of Endotoxemia in the Diabetic Mice
}

\author{
Yan Yang ${ }^{a}$ Ruolan Dong ${ }^{a}$ Danli Hu ${ }^{a}$ Zhihui Chen ${ }^{a}$ Menglu Fu ${ }^{a}$ Dao Wen Wang ${ }^{b}$ \\ Xizhen $\mathrm{Xu}^{\mathrm{b}}$ Ling $\mathrm{Tu}^{\mathrm{a}}$ \\ aDepartment of Geriatric Medicine, Tongji Hospital, Tongji Medical College, Huazhong University of \\ Science and Technology, Wuhan, ${ }^{\text {b}}$ The Institute of Hypertension and Department of Internal Medicine, \\ Tongji Hospital, Tongji Medical College, Huazhong University of Science and Technology, Wuhan, China
}

\section{Key Words}

Diabetes mellitus • Endotoxemia $\cdot$ AMP-activated protein kinase $\cdot$ Inflammatory response $•$ LPS • Endothelial permeability

\begin{abstract}
Background/Aims: Sepsis is a common disease that continues to increase in prevalence worIdwide, and diabetes mellitus may make the situation worse. This study was designed to determine the role of Liver Kinase B1 (LKB1)/adenosine monophosphate-activated protein kinase (AMPK) signaling pathway in diabetic mice complicated with systemic endotoxemia. Methods: The effects of LKB1/AMPK signaling pathway activation on endotoxemia were investigated in streptozotocin induced diabetic mice (STZ-mice) and db/db diabetic mice. Primary peritoneal macrophages and human umbilical vein endothelial cells (HUVECs) monolayers were simultaneously stimulated by both high glucose and LPS and used as a model to investigate the potential molecular mechanisms in vitro. Results: After treatment with LPS, high glucose or both LPS and high glucose, phosphor-AMPK expression was decreased, and moreover, AMPK activation by metformin treatment alleviated the decrease in phosphor-AMPK expression in HUVECs and macrophages as well as in lung tissue. Furthermore, both LPS and high glucose co-treatment decreased LKB1 and phosphor-AMPK expression via enhanced oxidative stress response, and importantly, LKB1 overexpression mediated by adenovirus inhibited the decrease in phosphor-AMPK expression in macrophages and HUVECs. AMPK activation by metformin administration improved the survival of STZ-induced diabetic mice and $\mathrm{db} / \mathrm{db}$ diabetic mice, which was associated with reduced lung endothelial hyperpermeability and systemic inflammatory response. Furthermore, the permeability of HUVECs monolayers induced by both high glucose and LPS stimulation was also alleviated by AMPK activation, which was partly via suppression of VE-cadherin phosphorylation. Conclusion: These data demonstrated that LKB1/AMPK signaling pathway activation improved the survival of diabetic mice complicated




\section{Cellular Physiology Cell Physiol Biochem 2017;42:761-779 and Biochemistry \begin{tabular}{l|l} 
DoI: 10.1159/000478068 \\
Publisned onine: June 19, 2017 & $\begin{array}{l}\text { O } 2017 \text { The Author(s). Published by S. Karger AG, Basel } \\
\text { www.karger.com/cpb }\end{array}$ \\
\cline { 1 - 2 }
\end{tabular}

with endotoxemia. Thus, LKB1/AMPK signaling pathway may serve as a potentially useful therapeutic target for severe infection in diabetic patients.

\section{Introduction}

Accounting for an estimated $22 \%$ of deaths in diabetic patients, infection is a common and serious complication of diabetes, as well as a well-recognized cause of mortality [1, 2]. Previous data indicates that diabetic mice have increased susceptibility to a variety of bacterial infections $[3,4]$. Despite the poor prognosis of diabetes complicated with sepsis, very little is known about the mechanisms that confer the increased susceptibility to mortality induced by endotoxemia during diabetes.

Sepsis is a systemic inflammatory response to infections, involving a termed systemic inflammatory response syndrome (SIRS). Lipopolysaccharide (LPS), the outer membrane of Gram-negative bacteria, is an important trigger of sepsis [5]. A profound pro-inflammatory response occurs in sepsis, resulting in immunological imbalance [6, 7]. Macrophages and monocytes are prominent innate immune cells responding to LPS with the production of inflammatory mediators including TNF- $\alpha$ and IL-6. A great number of monocytes and macrophages infiltrate in alveoli, which can cause pulmonary vessels damage and increase lung vascular/epithelial permeability. In the final stage of sepsis, the interaction between the severe infection and hyperactive inflammatory response causes progressive systemic organs failure [8]. Acute respiratory distress syndrome (ARDS), mainly characterized by leukocytes infiltration and pulmonary permeability edema, is a major complication in sepsis due to a disruption of the epithelial and endothelial barriers [9]. These pathophysiological changes contribute to lung edema and poor compliance. Consequently, septic diabetes patients suffering from shock and acute respiratory distress syndrome experience high mortality.

Evidence suggests that cellular energy metabolism is involved in inflammation suppression, although the exact mechanisms are not fully elucidated $[10,11]$. AMP-activated protein kinase (AMPK), a heterotrimeric serine/threonine kinase constitutes with catalytic $\alpha$ subunit, regulatory $\beta$ and $\gamma$ subunits, is a sensor of intracellular energy status and participates in the cellular response to metabolic stress. Previous studies show AMPK activation by salvianolic acid A or salvianolic acid B has antidiabetic effect in diabetic animal models $[12,13]$. Recent studies have demonstrated that AMPK activation can inhibit inflammation $[14,15]$. Metformin and berberine, which activate AMPK, act as an effective drug to treat inflammation-related diseases [16-18]. Furthermore, AMPK activity is deceased in obesity, type 2 diabetes and these linked metabolic disorders associated with low-grade inflammation in adipose tissue [19]. However, the role of AMPK activation in diabetes mellitus with severe infection remains poorly defined.

We are interested in determining whether LKB1/AMPK signaling pathway activation can improve the survival of sepsis in diabetic mice. In this study, STZ-induced and $\mathrm{db} / \mathrm{db}$ diabetic mice were used to establish the models of sepsis. The promising role of LKB1/ AMPK signaling pathway activated by metformin on survival of sepsis was evaluated, and the underlying mechanisms were explored.

\section{Materials and Methods}

\section{Reagents}

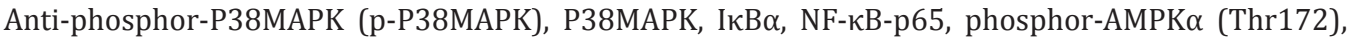
AMPK $\alpha$, Ser79-phosphorylated acetyl coenzyme A carboxylase (p-ACC), acetyl coenzyme A carboxylase and LKB1 antibodies were obtained from Cell Signaling Technology (Beverly, MA). Anti-vascular endothelial cadherin (VE-cadherin), Tyr658-phosphorylated VE-cadherin, ZO-1, claudin-5, Lamin B1, $\beta$-actin, CD68 antibodies were purchased from Santa Cruz Biotechnology (Santa Cruz, CA). Anti-4-HNE antibody was 


\section{Cellular Physiology Cell Physiol Biochem 2017;42:761-779

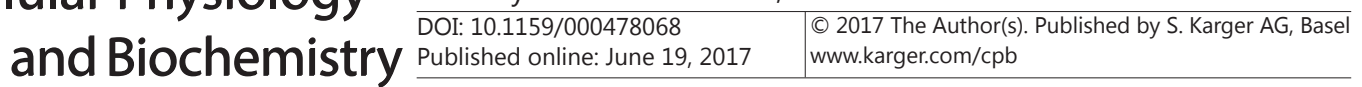 \\ Yang et al.: LKB1/AMPK Signaling Pathway Activation Improved the Survival of Sepsis in Diabetic Mice}

purchased from Abcam (Cambridge, UK). Horseradish peroxidase-conjugated secondary antibodies were purchased fromgThermodFisherfScientific.eMetformin, 5 - Aminoimidazole - 4 - carboxamide - 1 - D ribofuranoside (AICAR), lipopolysaccharide (LPS, from Escherichia coli 055:B5) and all other chemicals were purchased from Sigma-Aldrich (St. Louis, MO) unless otherwise indicated.

\section{Animals}

$\mathrm{C} 57 \mathrm{BL} / 6 \mathrm{~J}$ and $\mathrm{db} / \mathrm{db}$ mice were purchased from the Experimental Animal Center of Shanghai (Shanghai, People's Republic of China). All procedures were approved by the Animal Research Ethics Board at Huazhong University of Science and Technology and conformed to Directive 2010/63/EU of the European Parliament. Mice were given daily intraperitoneal injections of $60 \mathrm{mg} / \mathrm{kg}$ of streptozotocin (Sigma-Aldrich, St. Louis, MO) dissolved in $0.1 \mathrm{M}$ sodium citrate $(\mathrm{pH} \mathrm{4.5)}$ for five consecutive days. Blood glucose levels, body weight, and diabetes incidence were monitored weekly. Mice with hyperglycemia (blood sugar $\geq 300$ $\mathrm{mg} / \mathrm{dl}$ after two consecutive determinations under non-fasting conditions) and polyuria were considered diabetic. LPS (15 mg/kg, i.p.) dissolved in saline was administered only once either to control mice or STZdiabetic mice. Mice were orally administered with either saline or metformin ( $400 \mathrm{mg} / \mathrm{kg}$, bid) for 3 days prior to the injection of LPS (15 mg/kg, i.p.). At 24 and $48 \mathrm{~h}$ after the onset of endotoxaemia, animals were correspondingly administered with either saline or metformin. Survival of mice was recorded for $100 \mathrm{~h}$ after the LPS injection. Tissues and blood sample were harvested and stored at $-80^{\circ} \mathrm{C}$ until required.

\section{Evans Blue Staining in Lungs}

Accumulation of Evans Blue dye in lung tissue was evaluated according to a protocol described previously [20]. In brief, Evans Blue dye (30 mL/kg) was injected into the tail vein 2 hours before sacrifice. At the end of the experiment, a thoracotomy was performed and the lungs were perfused with PBS containing $5 \mathrm{mmol} / \mathrm{L}$ of EDTA to remove blood. Both left and right lobes of the lung were excised. Evans Blue accumulation in the lung tissue was measured by spectrofluorometric analysis of lung tissue lysates.

\section{Lung wet/dry weight ratio}

The wet/dry weight ratio is an indicator of lung edema. The ratio was calculated by dividing the wet weight by the dry weight. The middle lobe of the right lung was excised and the wet weight was recorded, and the lung was then placed in an incubator at $80^{\circ} \mathrm{C}$ for $24 \mathrm{~h}$ to obtain the dry weight.

\section{Histological analysis}

Lung tissues were harvested, fixed in $4 \%$ paraformaldehyde, and embedded in paraffin for histological analysis. Hematoxylin-eosin staining was performed to observe the pathological changes in lung tissues. Immunohistochemical staining was performed using antibody against CD68.

\section{Isolation and culture of murine peritoneal macrophages}

Murine peritoneal macrophages were isolated essentially as described previously [21]. Briefly, 8- to 10 -week-old mice were i.p. injected with $1 \mathrm{ml}$ of $4 \%$ Brewer thioglycollate medium. After 3 days of injection, peritoneal cells were washed with $10 \mathrm{ml}$ of ice-cold Hanks' balanced salt solution (HBSS) (free of calcium and magnesium). Media prepared from peritoneum were centrifuged at 12,000 rpm for 5 minutes. The pellet was resuspended in RBC lysis buffer (BioLegend, San Diego, CA) and then centrifuged at 12,000 rpm for 5 minutes. After washing with $20 \mathrm{ml}$ of HBSS, cells were seeded on six-well culture slides $\left(4 \times 10^{5}\right.$ cells $/$ well). These cells were allowed to adhere for $2 \mathrm{~h}$ and then were washed out with $1 \times$ phosphate-buffered saline to remove non-adherent cells. After 24 hours of culture, adherent cells were used for the indicated experiments.

\section{Cell culture and treatments}

The Human Umbilical Vein Endothelial cells (HUVECs) were purchased from ATCC. Cells were grown in RPMI 1640 (Gibco) medium, supplemented with 10\% fetal bovine serum (FBS), 100U/ml penicillin and $100 \mu \mathrm{g} / \mathrm{ml}$ streptomycin in a humidified atmosphere of $5 \% \mathrm{CO} 2$ at $37^{\circ} \mathrm{C}$. Cells were incubated with normal (5.5 $\mathrm{mM}$ ) or high $(25 \mathrm{mM})$ concentrations of D-glucose (Sigma, St. Louis, MO, USA) for $24 \mathrm{~h}$ in medium with $2 \%$ serum (to maintain the cells in the quiescent state) and then treated with or without metformin $(5 \mathrm{mM}) /$ AICAR $(1 \mathrm{mM})$ for $2 \mathrm{~h}$ before LPS $(1 \mu \mathrm{g} / \mathrm{ml})$ treatment for $6 \mathrm{~h}$. Differences in osmolarity between 


\section{Cellular Physiology Cell Physiol Biochem 2017;42:761-779 \\ \begin{tabular}{ll|l} 
and Biochemistry & $\begin{array}{l}\text { DOI: 10.1159/000478068 } \\
\text { Publisned onlne: June 19, } 2017\end{array}$ & $\begin{array}{l}\text { ( ) 2017 The Author(s). Published by S. Karger AG, Basel } \\
\text { www.karger.com/cpb }\end{array}$ \\
\hline
\end{tabular} \\ Yang et al.: LKB1/AMPK Signaling Pathway Activation Improved the Survival of Sepsis in Diabetic Mice}

normal glucose and high glucose media were corrected by adding $19.5 \mathrm{mM}$ of mannitol to the normal glucose medium.

\section{In vitro permeability}

HUVECs were seeded onto gelatin-coated, 24-well Transwell 3.0- $\mu$ m pore-size culture inserts (Corning Life Sciences, Lowell, MA) at a density of 0.1 million cells/well and cultured for $72 \mathrm{~h}$ to form restrictive endothelial monolayers. HUVECs were incubated with normal $(5.5 \mathrm{mM})$ or high $(25 \mathrm{mM})$ concentrations of D-glucose for $24 \mathrm{~h}$ and then treated with or without AICAR (1mM) for $2 \mathrm{~h}$ before LPS treatment $(1 \mu \mathrm{g} /$ $\mathrm{ml}$ ) for $6 \mathrm{~h}$. The permeability of HUVEC monolayers was determined by measuring the apical-to-basolateral movements of fluorescein isothiocyanate (FITC) dextran ( $40 \mathrm{kDa}$ ) (Sigma, St. Louis, MO). The test molecule was added to the apical compartment of the cells in a concentration of $100 \mu \mathrm{g} / \mathrm{ml}$. Samples $(200 \mu \mathrm{L})$ were collected from the basolateral side at baseline 75 minutes after the addition of the molecules. The medium in the basolateral compartment was replaced by fresh medium after the collection of every sample. A minimum of four wells were used for each measurement. Absorbance was measured at $485 \mathrm{~nm}$ of excitation and $528 \mathrm{~nm}$ of emission with a microplate reader (SpectraMax Gemini; Molecular Devices, Sunnyvale, CA).

\section{Generation of recombinant adenoviruses and transfection}

Recombinant adenovirus containing full-length murine LKB1 cDNA was prepared by homologous recombination of expression cosmid cassettes containing the corresponding cDNAs and the parental adenovirus genome, as described previously [22]. Adenovirus expressing GFP was used as a control. The amplified adenoviruses were purified and concentrated using cesium chloride ultracentrifugation. The resultant viruses were then dialyzed into phosphate-buffered saline. For adenovirus mediated transfection, cultured cells were incubated with medium containing the adenoviruses for $2 \mathrm{~h}$ at $37^{\circ} \mathrm{C}$, and the growth medium was then added. Experiments were performed 3 days after transfection. Using these conditions, infection efficiency was typically $>80 \%$ as determined by GFP expression.

\section{Quantitative real-time PCR}

Total RNA extracts were isolated from peritoneal macrophages lysates using Trizol reagent (Invitrogen, USA) following the manufacturer's instructions. Total RNA was reversely transcribed using the TransScript First-Strand cDNA Synthesis kit and quantitative real-time PCR was performed on an ABI7900 PCR system (Applied Biosystems, Darmstadt, Germany) using the TransStart ${ }^{\mathrm{TM}}$ Eco Green qPCR Kit (Qiagen, Valencia, CA). The sequences of the sense and antisense primers used for amplification were as follows: TNF- $\alpha$, 5'-CCCTCACACTCAGATCATCTTCT-3't (forward)2and45'-GCTACGACGTGGGCTACAG-3'2 (reverse);2IL-6,25'TAGTCCTTCCTACCCCAATTTCC-3'2(forward)2and25'-TTGGTCCTTAGCCACTCCTTC-3'2(reverse);2MCP1,25'-TTAAAAACCTGGATCGGAACCAA-3'2 (forward) 2and 25' -GCATTAGCTTCAGATTTACGGGT3'2 (reverse) ; 2 IL-1 $13,25^{\prime}$-TACAAGGAGAAGAAAGTAAT GAC AA - 3'2 (forward) 2 a nd 2 5' AGCTTGTTATTGATT TCTATCT TGT-3'2 (reverse);2 GAPDH,25' - GGTGAAG GT CGGTGTGAACG3'2(forward)2and25'-CTCGCTCCTGGAAGATGGTG-3' (reverse). The relative expression level of target genes normalized to GAPDH was calculated as $2^{-\triangle \Delta C T}$. Samples were analyzed in triplicate and every experiment was performed for at least three independent times.

\section{ELISA and Western blotting analysis}

TNF- $\alpha$, IL-1 $\beta$, IL-6, and MCP-1 levels in serum and cell culture supernatants were measured using ELISA kits according to the manufacturer's instructions (Boster Bio, Pleasanton, CA).

Western blot was performed as previously described [23]. Briefly, equal amounts of protein were separated on a $10 \%$ sodium dodecyl sulfate polyacrylamide gel electrophoresis (SDS-PAGE) and electrophoretically transferred onto polyvinylidene difluoride (PVDF) membranes. The membranes were incubated with $5 \%$ non-fat dry milk in TBST for $2 \mathrm{~h}$, then incubated overnight at $4^{\circ} \mathrm{C}$ with the indicated primary antibodies. The blots were developed with an enhanced chemiluminescence reagent kit. All groups were then normalized to their respective controls, and bar graphs represent quantification of at least 3 independent experiments. 


\section{Cellular Physiology Cell Physiol Biochem 2017;42:761-779

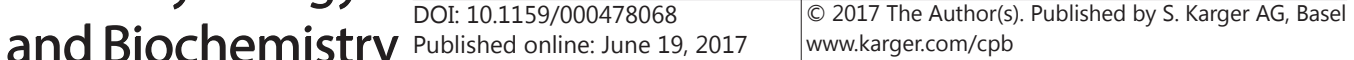 \\ Yang et al.: LKB1/AMPK Signaling Pathway Activation Improved the Survival of Sepsis in Diabetic Mice}

Immunoprecipitation of 4-HNE-LKB1 adducts

Immunoprecipitation assay using a Pierce Co-Immunoprecipitation kit (Pierce Biotechnology Ltd., Rockford, IL) was performed with cells lysed in immunoprecipitation buffer. Proteins (500 $\mu \mathrm{g}$ ) were immunoprecipitated overnight at $4{ }^{\circ} \mathrm{C}$ on a rotating platform with $50 \mu \mathrm{L}$ protein G-agarose covalently conjugated to anti-LKB1 (Ley37D/G6, Santa Cruz Biotechnology) antibody. Immunocomplexes were detected by Western blot with monoclonal antibody against 4-HNE-adducts (Abcam).

\section{Statistical analysis}

The continuous data was expressed as mean \pm SEM. Differences between groups were assessed by one-way or two-way analysis of variance, One-way ANOVA was used with post hoc analysis performed by the Student-Newman-Keuls method, and two-way ANOVA was also used with post hoc analysis performed by Bonferroni's Multiple Comparison test. The Kaplan-Meier method was used to examine the differences in mortality rates between groups. $P<0.05$ was accepted as statistically significant.

\section{Results}

High glucose and LPS co-stimulation decreased phosphor-AMPK expression in HUVECS and peritoneal macrophages

To examine the effect of high glucose and LPS co-stimulation on the expression of phosphor-AMPK, human umbilical vein endothelial cells (HUVECs) and peritoneal macrophages were cultured. The expression level of phosphor-AMPK was analyzed by western blotting. Metformin (1,1-dimethylbiguanide hydrochloride) is one of the most widely prescribed drugs for the treatment of type 2 diabetes. The main molecular target of metformin is AMP-activated protein kinase (AMPK) activation. To determine suitable drug concentration, confluent mouse peritoneal macrophages and HUVECs were treated with metformin at various concentrations for 2 hours. As shown in Fig. $1 \mathrm{~A}$ and 1B, metformin activated AMPK in a dose-dependent manner. In addition, metformin $(10 \mathrm{mM})$ maximally induced AMPK phosphorylation in both cell types, and metformin (10mM) was used in the following experiments. As shown in Fig. 1C and 1D, high glucose and LPS co-stimulation markedly decreased phosphor-AMPK and phosphorylated acetyl CoA carboxylase (ACC) expression, and metformin administration partly prevented these changes in HUVECs and peritoneal macrophages treated with both high glucose and LPS. Interestingly, the downregulation of LKB1, phosphor-AMPK and phosphor-ACC expression was confirmed in lung tissue of mice treated with both STZ and LPS. Moreover, metformin administration partly reversed these changes in lung tissue of mice as shown in Fig. 1E. These data indicated that the expressions of phosphor-AMPK were down-regulated in diabetic endotoxemia conditions, and moreover, activation of AMPK may have the potential of anti-inflammatory effects.

Metformin did not modify physiological parameters in STZ-treated mice and $\mathrm{db} / \mathrm{db}$ mice

Mice were rendered diabetic by intraperitoneal injection of STZ ( $60 \mathrm{mg} / \mathrm{kg}$, i.p, ×5d), and then administered by oral gavage of metformin $(400 \mathrm{mg} / \mathrm{kg}$ ) for 3 days before and 2 days after LPS challenge. As shown in Table 1, compared with control mice, STZ-treated mice exhibited a significant reduction in body weight $(17.5 \pm 0.2 \mathrm{~g}$ vs. $25.3 \pm 0.3 \mathrm{~g}, \mathrm{p}<0.01)$ and elevation in blood glucose level (380 $\pm 16.4 \mathrm{mg} / \mathrm{dl}$ vs. $136 \pm 4.5 \mathrm{mg} / \mathrm{dl}, \mathrm{p}<0.01)$. Metformin $(400$ $\mathrm{mg} / \mathrm{kg}, \times 5 \mathrm{~d}$ ) did not modify body weight and blood glucose level of STZ-treated mice (body weight: $18.4 \pm 0.2 \mathrm{~g}$; blood glucose: $396 \pm 14.6 \mathrm{mg} / \mathrm{dl}$ ). Moreover, oral gavage of metformin $(400 \mathrm{mg} / \mathrm{kg}$ ) for 5 days in control mice did not change the body weight ( $24.7 \pm 0.3 \mathrm{~g}$ vs. 25.3 $\pm 0.3 \mathrm{~g}, \mathrm{p}>0.05)$ and blood glucose level $(133 \pm 3.9 \mathrm{mg} / \mathrm{dl} \mathrm{vs} .136 \pm 4.5 \mathrm{mg} / \mathrm{dl}, \mathrm{p}>0.05)$. We also explored whether metformin affected serum lipid and glucose metabolism in $\mathrm{db} / \mathrm{db}$ mice (Table 2). The body weights, blood glucose, serum cholesterol levels and triglyceride levels of $\mathrm{db} / \mathrm{db}$ mice were higher than non-diabetic mice. However, there was no difference in these metabolic parameters between mice treated with and without metformin. 


\section{Cellular Physiology Cell Physiol Biochem 2017;42:761-779 \begin{tabular}{c|c|c|c|} 
DOI: 10.1159/000478068 & O 2017 The Author(s). Published by S. Karger AG, Basel \\
\hline
\end{tabular} \\ Yang et al.: LKB1/AMPK Signaling Pathway Activation Improved the Survival of Sepsis in Diabetic Mice}

Table 1. Physiological parameters determined in mice administered by oral gavage of metformin for 5 days. Data are presented as mean \pm SD, ${ }^{* *} P<0.01$ vs control

\begin{tabular}{lcccc}
\hline & control & STZ & control+Met & STZ+Met \\
& $\mathrm{n}=9$ & $\mathrm{n}=10$ & $\mathrm{n}=9$ & $\mathrm{n}=8$ \\
\hline Body weight, $\mathrm{g}$ & $25.3 \pm 0.3$ & $17.5 \pm 0.2^{* *}$ & $24.7 \pm 0.3$ & $18.4 \pm 0.2$ \\
Blood glucose, $\mathrm{mg} / \mathrm{dl}$ & $136 \pm 4.5$ & $380 \pm 16.4^{* *}$ & $133 \pm 3.9$ & $396 \pm 14.6$ \\
\hline
\end{tabular}

Table 2. Effects of metformin on body weight, blood glucose and lipid profiles in control lean mice and $\mathrm{db} /$ $\mathrm{db}$ mice. Data are presented as mean \pm SD, ${ }^{* *} P<0.01$ vs lean

\begin{tabular}{lcccc}
\hline & $\begin{array}{c}\text { lean } \\
\mathrm{n}=6\end{array}$ & $\begin{array}{c}\mathrm{db} / \mathrm{db} \\
\mathrm{n}=9\end{array}$ & $\begin{array}{c}\text { lean }+ \text { Met } \\
\mathrm{n}=8\end{array}$ & $\begin{array}{c}\mathrm{db} / \mathrm{db}+\text { Met } \\
\mathrm{n}=7\end{array}$ \\
\hline Body weight, $\mathrm{g}$ & $23.6 \pm 0.4$ & $46.5 \pm 0.8^{* *}$ & $24.4 \pm 0.5$ & $45.4 \pm 0.6$ \\
Blood glucose, $\mathrm{mg} / \mathrm{dl}$ & $145 \pm 5.3$ & $335 \pm 13.7^{* *}$ & $141 \pm 6.3$ & $344 \pm 12.7$ \\
Cholesterol, $\mathrm{mmol} / \mathrm{L}$ & $2.5 \pm 0.2$ & $4.8 \pm 0.4^{* *}$ & $2.5 \pm 0.5$ & $4.7 \pm 0.6$ \\
Triglycerides, $\mathrm{mmol} / \mathrm{L}$ & $1.0 \pm 0.1$ & $2.5 \pm 0.3^{* *}$ & $1.1 \pm 0.2$ & $2.7 \pm 0.2$ \\
\hline
\end{tabular}

Fig. 1. High glucose and LPS co-stimulation reduced phosphor-AMPK expression in HUVECs and peritoneal macrophages. (A) Mouse peritoneal macrophages and (B) HUVECs were incubated with the indicated concentrations of metformin for $2 \mathrm{~h}$ and immunoblotting showed that metformin induced AMPK phosphorylation peaked at $10 \mathrm{mM}$. ${ }^{* *} P$ $<0.01,{ }^{*} P<0.05$ vs. control. Cells were incubated with normal (5.5 mM) or high (25 $\mathrm{mM}$ ) D-glucose for 24 hours in medium and then treated with or without metformin ( $5 \mathrm{mM}$ ) for $2 \mathrm{~h}$ before LPS treatment $(1 \mu \mathrm{g} /$ $\mathrm{ml}$ ) for $6 \mathrm{~h}$. P-AMPK $\alpha$, AMPKo, p-ACC, and ACC expression in (C) HUVECs and (D) peritoneal macrophages

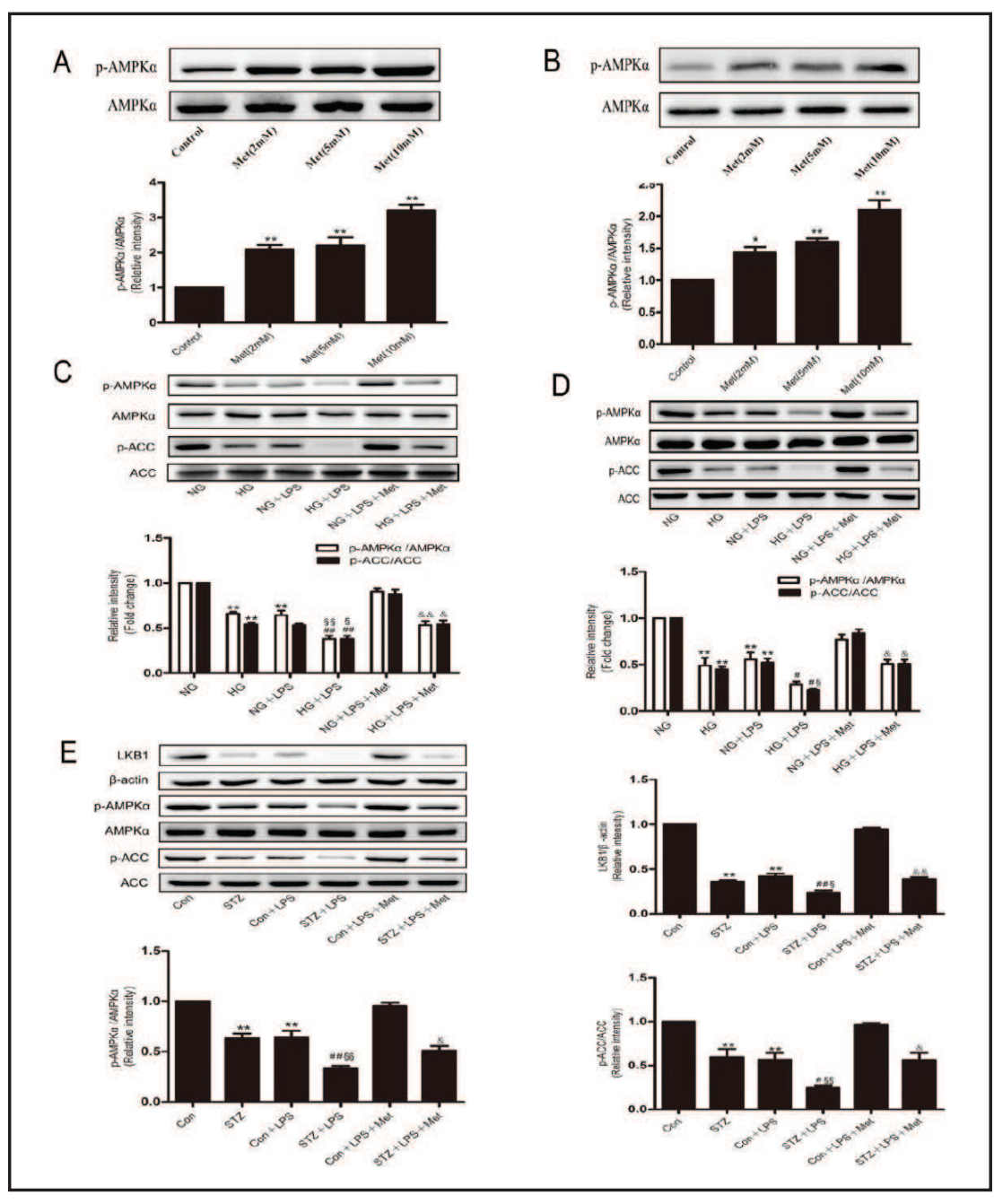
was assessed by immunoblotting and densitometry analysis. Control or STZ-diabetic mice were orally administered either saline or metformin (400 mg/kg, bid) for 3 days prior to the injection of LPS (10 mg/kg, i.p.); Lung tissues were collected. (E) Protein expression of LKB1, p-AMPK $\alpha$, AMPK $\alpha, \mathrm{p}-\mathrm{ACC}$, and ACC was assessed by immunoblotting and densitometry analysis. Data are shown as mean \pm SEM from three independent experiments. ${ }^{* *} P<0.01$ vs. NG; ${ }^{\# \# P<0.01, ~}{ }^{\#} P<0.05$ vs. NG + LPS; $\$ \S P<0.01,{ }^{\S} P<0.05$ vs. HG; ${ }^{\otimes} P<0.05$, ${ }^{凶} P<0.01$ vs. HG + LPS. $\mathrm{n}=6$ for each experiment, ${ }^{* *} P<0.01$ vs. control; ${ }^{\# \#} P<0.01,{ }^{\#} P<0.05$ vs. Con + LPS; ${ }^{\S} P<0.01,{ }^{\S} P<0.05$ vs. STZ; ${ }^{\circledR} P<0.05,{ }^{\otimes} P<0.01$ vs. STZ + LPS. The statistical analysis was from the one-way ANOVA.

\section{KARGER}




\section{Cellular Physiology Cell Physiol Biochem 2017;42:761-779 \begin{tabular}{ll|l} 
and Biochemistry & Dublisned on/ne: June 19, 2017 & $\begin{array}{l}\text { C 2017 The Author(s). Published by S. Karger AG, Basel } \\
\text { www.karger.com/cpb }\end{array}$ \\
\hline
\end{tabular} \\ Yang et al.: LKB1/AMPK Signaling Pathway Activation Improved the Survival of Sepsis in Diabetic Mice}

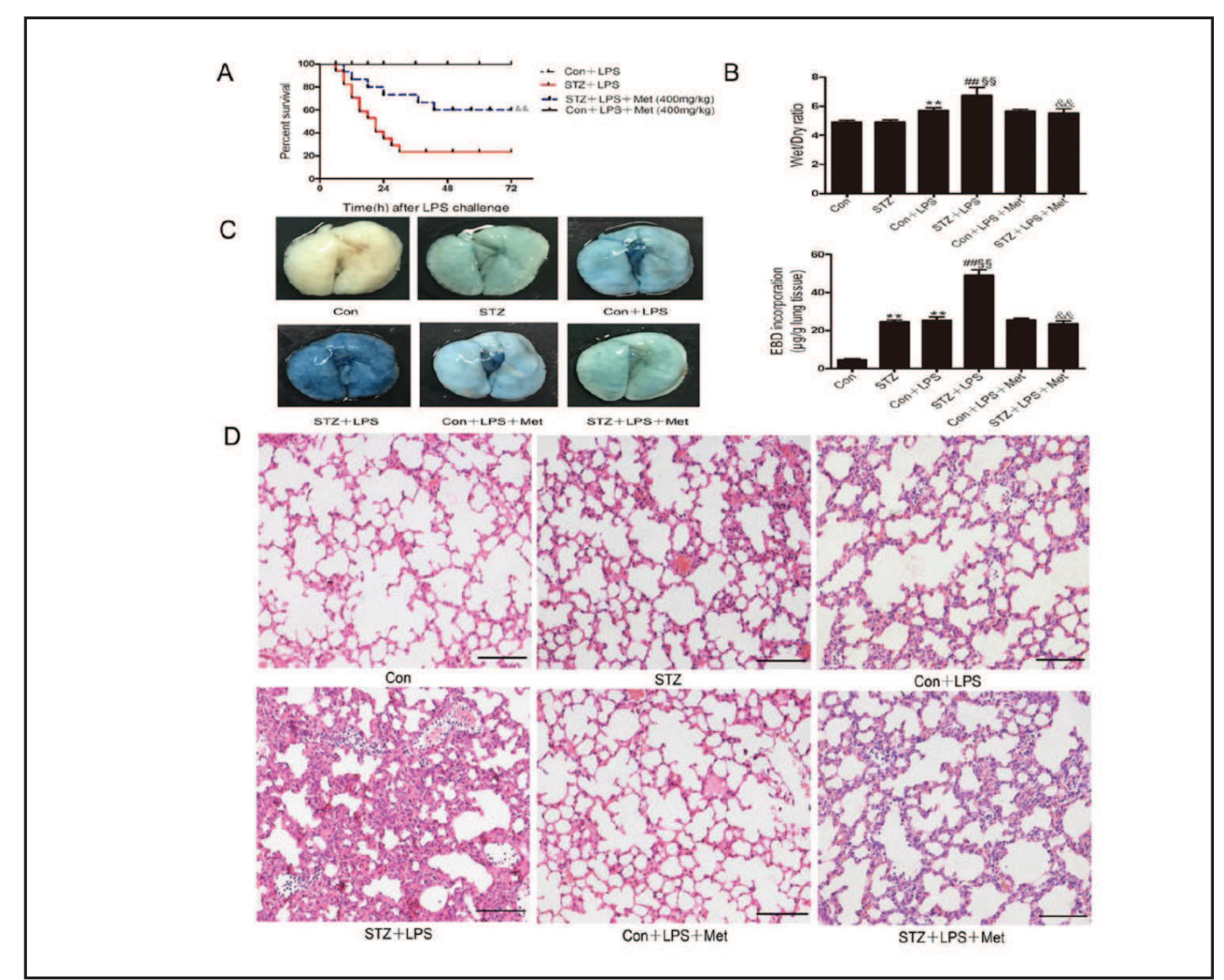

Fig. 2. Stimulation of AMPK increased survival and enhanced lung repair in LPS-treated streptozotocin (STZ) diabetic mice. (A) Survival time was evaluated after LPS or saline administration in the Con + LPS $(n=$ 10), STZ + LPS ( $n=17)$, STZ + LPS + Met $(n=15)$, and Con + LPS + Met ( $n=12)$ groups. (B) Wet/dry weight ratio that evaluates the extent of lung edema. (C) Lung vascular permeability was assessed by accumulation of Evans Blue dye in the lungs. Lung were excised after perfusion and imaged. Spectrophotometric analysis of Evans Blue-stained albumin content in the lung tissues was quantified. (D) Immunochemical evaluation of lung tissue by hematoxylin/eosin staining. Scale bars: $100 \mu \mathrm{m}$. The Kaplan-Meier program was utilized to compare the differences in mortality rates between groups. Data are shown as mean \pm SEM from three independent experiments. ${ }^{* *} P<0.01$ vs. control; ${ }^{\# \#} P<0.01$ vs. Con + LPS; $\$ \$ P<0.01$ vs. STZ; ${ }^{\& \&} P<0.01$ vs. STZ + LPS. The statistical analysis was from the two-way ANOVA.

\section{AMPK activation attenuates LPS-induced endotoxemia in diabetic mice}

To investigate the effect of AMPK activation on LPS-induced endotoxemia in diabetic conditions, mice were injected with LPS, with or without metformin pre-treatment. Remarkably, we found that $60 \%$ of the septic STZ-treated mice treated with metformin survived ( 9 of 15 mice) compared to $23.5 \%$ of untreated septic STZ-treated mice (4 of 17 mice, $\mathrm{p}<0.01$ ). While none of the mice died after LPS administration in the control group (Fig. 2A), but LPS treatment did cause the increase in the level of serum TNF- $\alpha$ and IL-6 as shown in Fig. 4, which indicated that LPS administration induced septic shock in mice of control group. To evaluate the effect of AMPK activation on LPS-induced changes in pulmonary vascular permeability, the lung wet/dry weight ratio was determined. As shown in Fig. 2B, LPS stimulation induced significant increase in wet/dry ratio in non-STZtreated mice, which was accentuated in STZ-treated mice. In comparison, such elevations were blunted by metformin treatment. To further assess the severity of the lung vascular leakage, we examined the leak index of Evans blue. As observed, LPS stimulation induced 


\section{Cellular Physiology Cell Physiol Biochem 2017;42:761-779

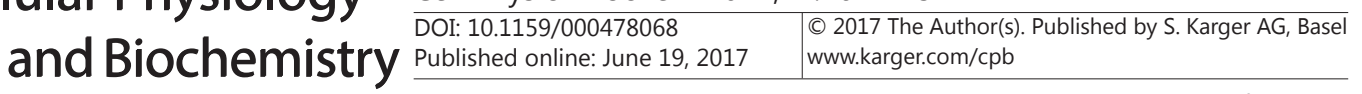 \\ Yang et al.: LKB1/AMPK Signaling Pathway Activation Improved the Survival of Sepsis in Diabetic Mice}

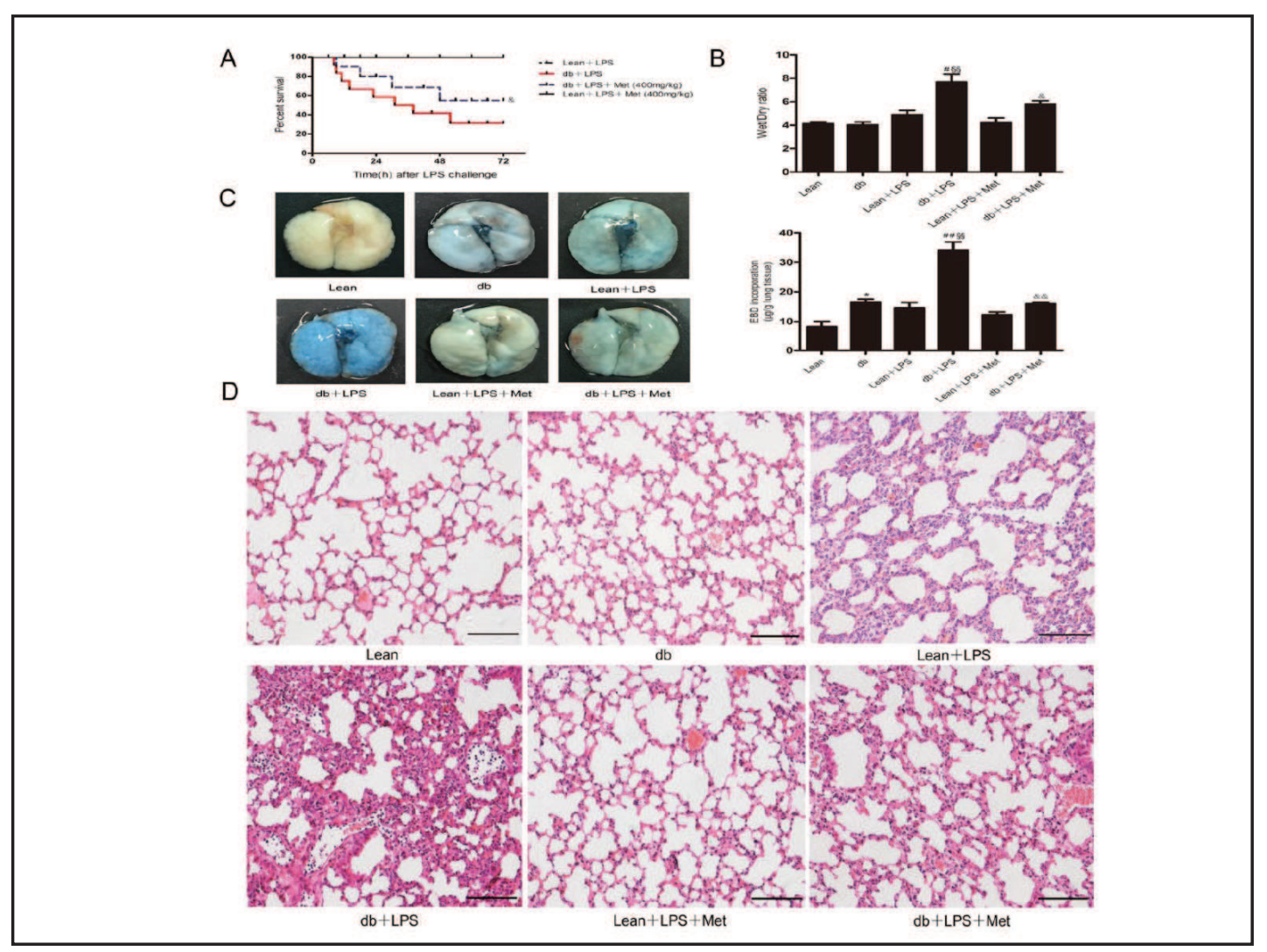

Fig. 3. Effects of metformin on the survival rate in $\mathrm{db} / \mathrm{db}$ mice after LPS administration. Mice were orally administered either saline or metformin ( $400 \mathrm{mg} / \mathrm{kg}$, bid) for 3 days prior to the injection of LPS (10 mg/kg, i.p.). At 24 and $48 \mathrm{~h}$ after the onset of endotoxaemia, animals were administered with either saline or metformin. (A) Survival time was monitored after LPS challenge in the Lean + LPS ( $n=10), d b / d b+\operatorname{LPS}(n=12)$, $\mathrm{db} / \mathrm{db}+$ LPS + Met $(\mathrm{n}=10)$ and Lean + LPS + Met $(\mathrm{n}=11)$ groups for $100 \mathrm{~h}$. (B) Wet/dry weight ratio that evaluates the extent of lung edema. (C) Lung vascular permeability was assessed by accumulation of Evans Blue dye in the lungs. Lungs were excised after perfusion and imaged. Spectrophotometric analysis of Evans Blue-stained albumin content in the lung tissues was calculated. (D) Immunochemical evaluation of lung tissue by H\&E staining. Scale bars: $100 \mu \mathrm{m}$. The Kaplan-Meier method was used to examine the differences in mortality rates between groups. $\mathrm{n}=4$ to 6 per group. ${ }^{*} P<0.05$ vs. Lean; ${ }^{\#} P<0.05,{ }^{\# \#} P<0.01$ vs. Lean + LPS; ${ }^{\S} P<0.01$ vs. db; ${ }^{\circledR} P<0.05,{ }^{\& \&} P<0.01$ vs. $d b+$ LPS. The statistical analysis was from the one-way ANOVA.

significant increase in Evans blue leakage in non-STZ-treated mice. While in STZ-treated mice, LPS induced greater increase in Evans blue leakage, which was obviously decreased by metformin administration (Fig. 2C). In addition, STZ + LPS treated mice displayed the most serious histopathological alterations, including cell structure destruction, white blood cells infiltration, alveolar wall thickening and lung hemorrhage, which was also attenuated by metformin treatment (Fig. 2D). These results suggest that AMPK activation by metformin protected against sepsis via decreased lung permeability induced by LPS treatment in streptozotocin triggered-diabetic mice.

Interestingly, the effects of AMPK activation on sepsis in diabetic conditions were further confirmed in $\mathrm{db} / \mathrm{db}$ mice. As shown in Fig. 3A, the survival rate in group of $\mathrm{db}+\mathrm{LPS}$ + Met was higher than that in the group of $\mathrm{db}+$ LPS, which was associated with decreased permeability characterized by low lung wet/dry ratio(Fig. 3B), Evans blue leakage (Fig. 3C) and alveolar exudation(Fig. 3D). These results suggest that AMPK activation by metformin protected against sepsis via decreased lung permeability induced by LPS treatment in $\mathrm{db}$ / $\mathrm{db}$ diabetic mice. Taken together, these results suggest that AMPK activation by metformin protected against sepsis partly via decreased lung permeability in diabetic mice. 


\section{Cellular Physiology \\ Cell Physiol Biochem 2017;42:761-779 \\ \begin{tabular}{ll|l} 
DOI: 10.1159/000478068 & $\begin{array}{l}\text { @ 2017 The Author(s). Published by S. Karger AG, Basel } \\
\text { www.karger.com/cpb }\end{array}$ \\
\cline { 2 - 3 }
\end{tabular} \\ Yang et al.: LKB1/AMPK Signaling Pathway Activation Improved the Survival of Sepsis in Diabetic Mice}

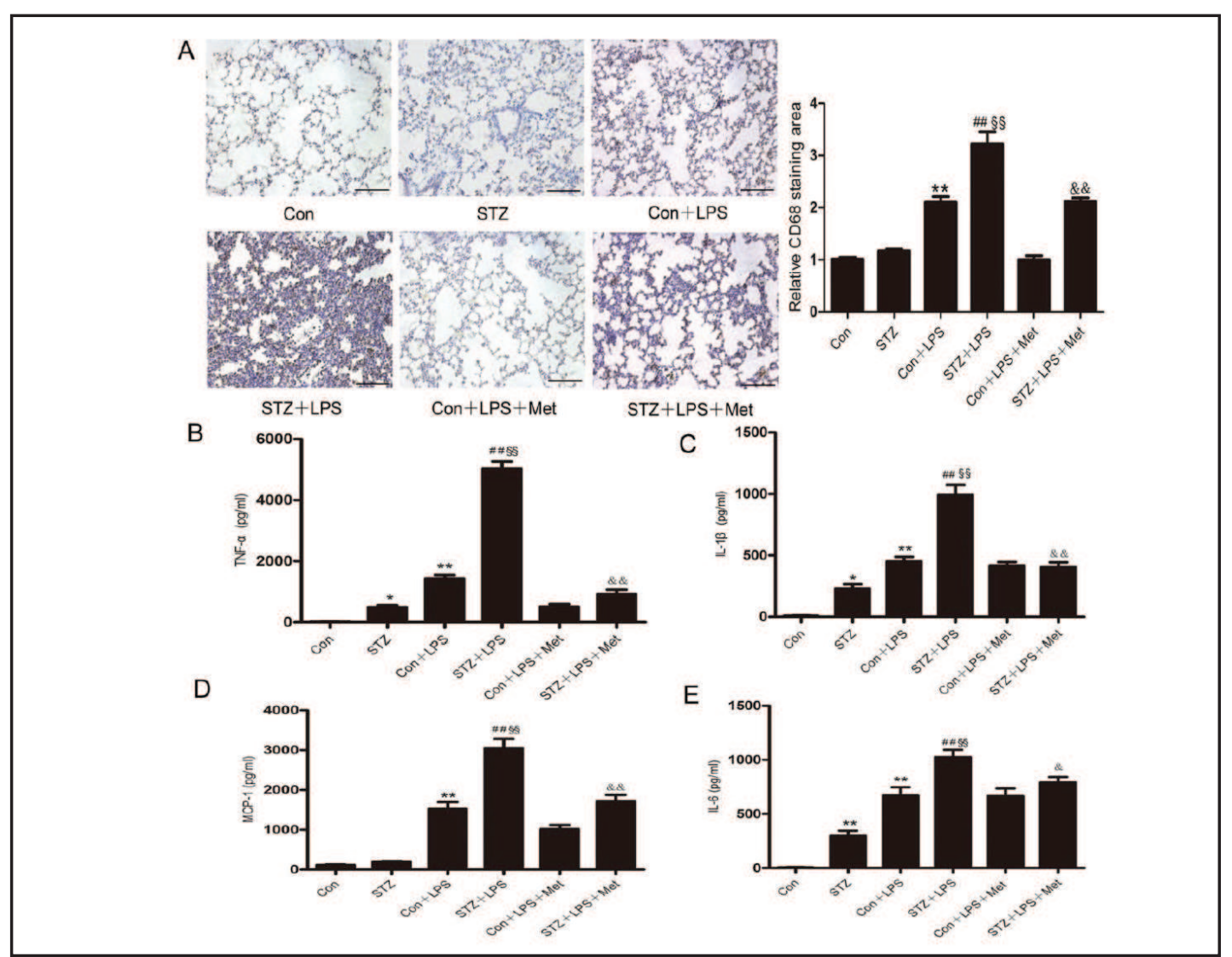

Fig. 4. Effects of metformin on serum levels of cytokines induced by lipopolysaccharide (LPS) in diabetic mice. (A) Immunohistochemical staining of CD68 in lung tissue sections were performed (Scale bars: 100 $\mu \mathrm{m} ; \mathrm{n}=5$ per group). Representative pictures of immunohistochemical detection of positive cells and quantification were shown. Serum cytokines levels of TNF $\alpha$ (B), IL-1 $\beta$ (C), MCP-1 (D) and IL-6 (E) were measured by ELISA $6 \mathrm{~h}$ after LPS $(15 \mathrm{mg} / \mathrm{kg})$ treatment. Data are shown as mean $\pm \mathrm{SEM}$; ${ }^{* *} P<0.01,{ }^{*} P<0.05$ vs.

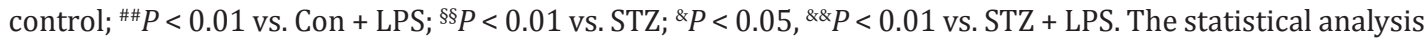
was from the two-way ANOVA.

AMPK activation was associated with decreased proinflammatory cytokines expression in STZ-treated mice after LPS administration

Previous study indicated that inflammatory response was involved in the pathogenesis of sepsis [7]. To investigate the effect of AMPK activation on inflammatory response in STZtreated mice, macrophages infiltration was determined by immunohistochemical staining. As expected, CD68 (marker of macrophages) positive area rarely appeared in lung tissue of control mice. Both STZ and LPS injection caused increased infiltration of CD68 positive cells. The CD68 positive area in the STZ + LPS group was significantly increased compared with that in Con + LPS group, whereas metformin treatment partly alleviated these effects as shown in Fig. 4A. In addition, a range of serum cytokines were also evaluated. As shown in Fig. 4B-E, LPS stimulation induced significant increase in levels of TNF- $\alpha$, IL-1 $\beta$, MCP-1, and IL-6 in non-STZ-treated mice. While in STZ-treated mice, LPS induced much higher level of these pro-inflammatory cytokines. Interestingly, metformin treatment partly but markedly prevented the increase in these cytokines levels induced by LPS + STZ. Collectively, these data indicated that AMPK activation by metformin was associated with decreased inflammatory response in diabetic mice treated with LPS. 


\section{Cellular Physiology Cell Physiol Biochem 2017;42:761-779 \begin{tabular}{l|l|l} 
DOI: $10.1159 / 000478068$ & (c) 2017 The Author(s). Published by S. Karger AG, Basel
\end{tabular} \\ Yang et al.: LKB1/AMPK Signaling Pathway Activation Improved the Survival of Sepsis in

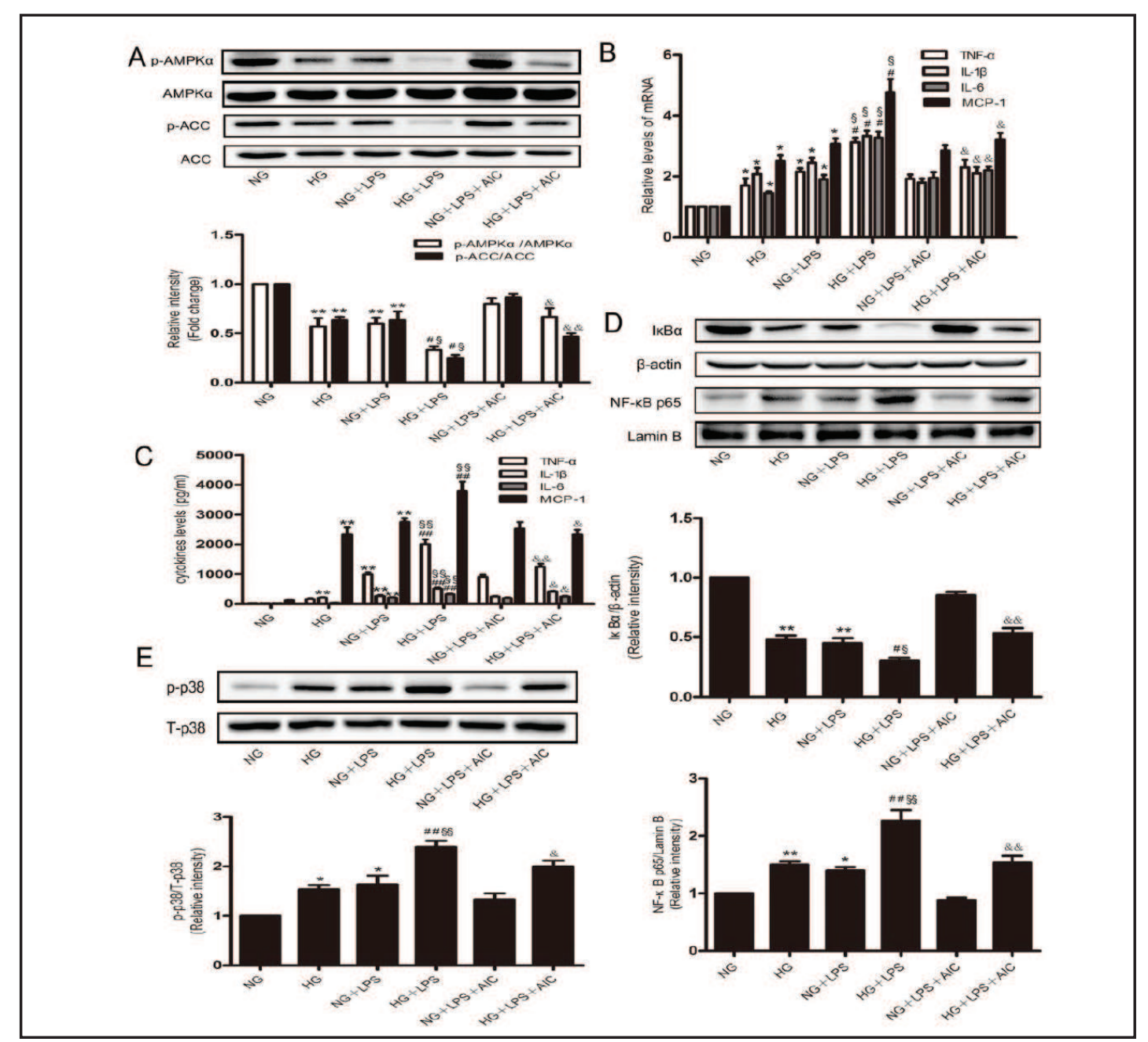

Fig. 5. AICAR inhibited lipopolysaccharide (LPS)-induced cytokines generation in peritoneal macrophages under high glucose conditions. (A) Representative immunoblots and quantitation of p-AMPK $\alpha$ and p-ACC expression. (B) Relative mRNA expression of TNF- $\alpha$ was assessed by quantitative real-time PCR after LPS stimulation for $1 \mathrm{~h}$ and other inflammatory genes (IL-1 $\beta$, IL-6, MCP-1) were determined after LPS stimulation for 3 h. (C) TNF- $\alpha$, IL-1 $\beta$, IL- 6 and MCP-1 were assessed by ELISA after LPS stimulation for 12 h. (D) Representative immunoblots and quantitation of $\mathrm{I} \kappa \mathrm{B} \alpha$, p 65 nuclear translocation. (E) p-p38 expression was determined by Western blot. Data are shown as mean \pm SEM from three independent experiments. ${ }^{* *} P<$ $0.01,{ }^{*} P<0.05$ vs. NG; ${ }^{\# \# P} P 0.01,{ }^{\#} P<0.05$ vs. NG + LPS; ${ }^{\S} P<0.01,{ }^{\S} P<0.05$ vs. HG; ${ }^{\circledR} P<0.05, \& \& P<0.01$ vs. $\mathrm{HG}+\mathrm{LPS}$. The statistical analysis was from the two-way ANOVA.

Activation of AMPK minimized cytokines expression induced by both high glucose and LPS stimulation in primary peritoneal macrophages

Thr172 is located in the activation loop of the AMPK $\alpha 1$ and $\alpha 2$ subunits, and its phosphorylation leads to AMPK activation [24]. To explore the potential mechanisms of AMPK activation on decreased inflammatory response, peritoneal macrophages, which were incubated in 5.5 or $25 \mathrm{mM}$ glucose (NG and $\mathrm{HG}$, respectively), were pretreated with AMPK activator AICAR ( $1 \mathrm{mM})$ for $2 \mathrm{~h}$, before the addition of LPS $(1.0 \mu \mathrm{g} / \mathrm{ml})$ for $6 \mathrm{~h}$ to induce the inflammatory response.

LPS or high glucose treatment alone decreased AMPK and acetyl coenzyme A carboxylase (ACC) at Ser79 phosphorylation. Moreover, both high glucose and LPS treatment significantly decreased the levels of AMPK and ACC phosphorylation. Whether under NG or HG conditions, the LPS-induced decrease in AMPK and ACC phosphorylation was significantly prevented by 


\section{Cellular Physiology \\ Cell Physiol Biochem 2017;42:761-779 \\ \begin{tabular}{ll|l} 
and Biochemistry & DOblished online: June 19, 2017 & $\begin{array}{l}\text { C 2017 The Author(s). Published by S. Karger AG, Basel } \\
\text { www.karger.com/cpb }\end{array}$ \\
\hline
\end{tabular} \\ Yang et al.: LKB1/AMPK Signaling Pathway Activation Improved the Survival of Sepsis in Diabetic Mice}
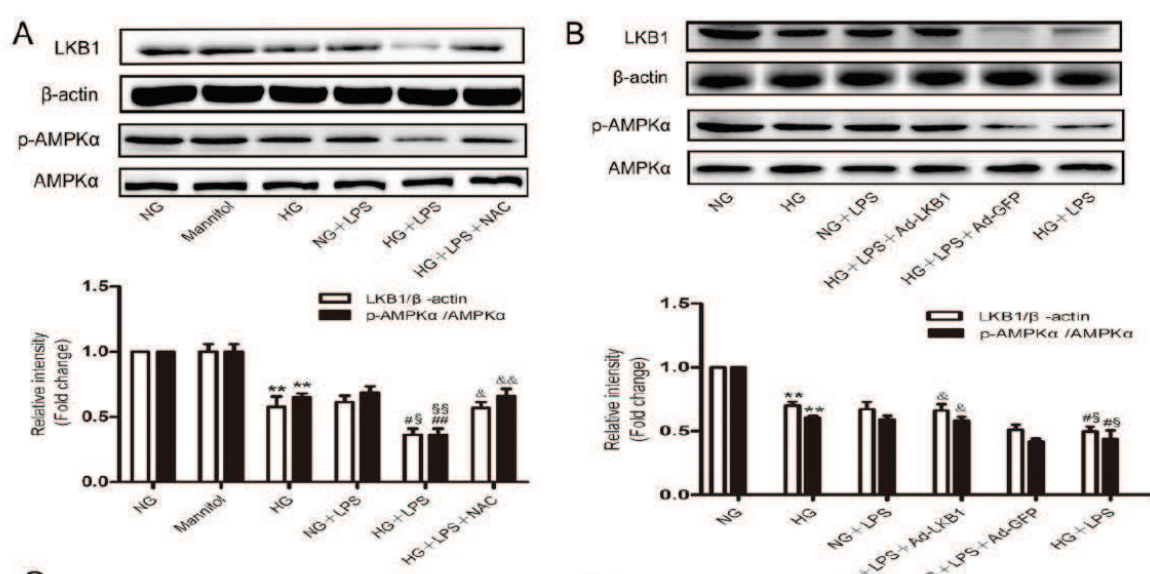

C
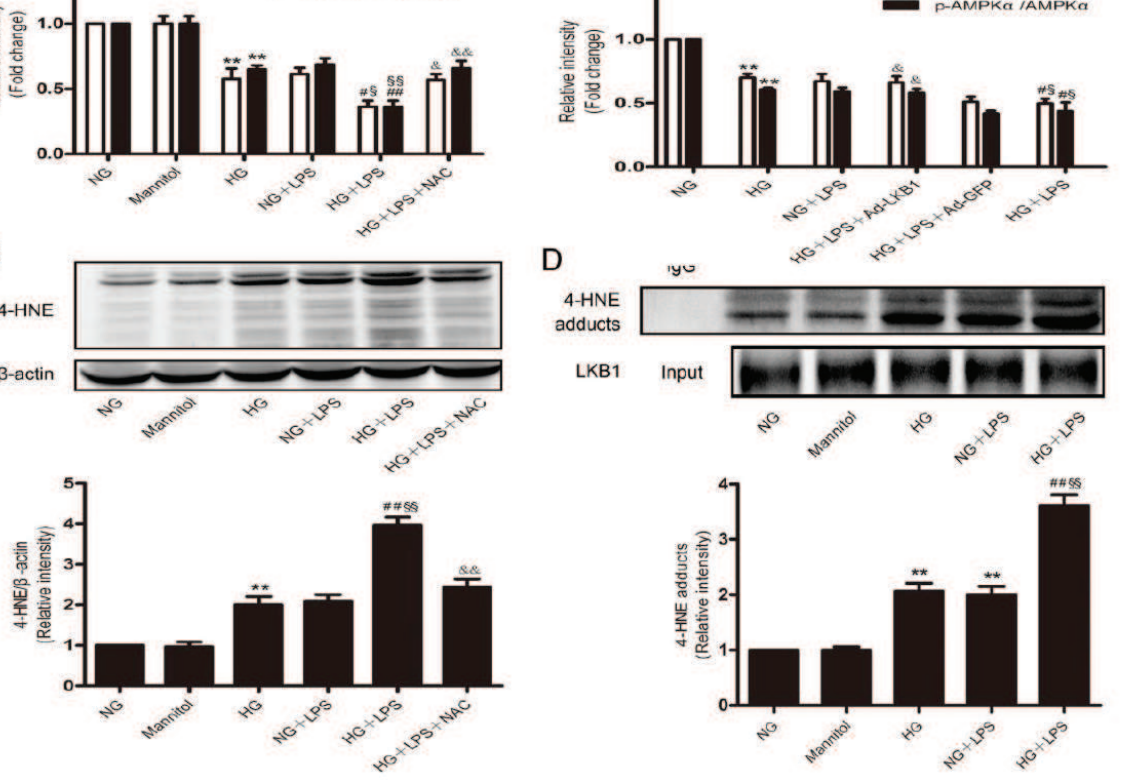

Fig. 6. High glucose and LPS-induced LKB1 reduction was mediated by oxidative stress in primary peritoneal macrophages. (A) LKB1, p-AMPK $\alpha$, AMPK $\alpha$, and $\beta$-actin expression was assessed by immunoblotting and densitometry analysis. (B) LKB1 overexpression activates AMPK signaling. Immunoblot analysis for LKB1, phosphorylated-AMPK $\alpha$ at Thr-172, total AMPK $\alpha$ was shown. Peritoneal macrophages were infected with Ad-GFP or Ad-LKB1 for $24 \mathrm{~h}$ before shift to HG with or without LPS administration. Data are shown as mean \pm SEM from three independent experiments. ${ }^{* *} P<0.01$ vs. NG; ${ }^{*} P<0.05$ vs. NG + LPS; ${ }^{\S} P<0.05$ vs. HG; ${ }^{\&} P<0.05$, vs. HG + LPS + Ad-GFP. (C) 4-hydroxy-2-nonenal (4-HNE) was examined by Western blot assay and quantified by densitometric analysis. (D) Immunoblot analysis with anti-HNE adduct antibody was performed on LKB1 immunoprecipitates from $500 \mu \mathrm{g}$ protein. Data are shown as mean \pm SEM from three independent experiments. ${ }^{* *} P<0.01$ vs. NG; ${ }^{\# \#} P<0.01,{ }^{\sharp} P<0.05$ vs. NG + LPS; ${ }^{\S} P<0.01,{ }^{\S} P<0.05$ vs. HG; ${ }^{\circledR} P$ $<0.05,{ }^{\& \&} P<0.01$ vs. HG + LPS. The statistical analysis was from the one-way or two-way ANOVA.

AMPK activator as shown in Fig. 5A. These data indicated that AMPK activation markedly prevented the decrease in AMPK phosphorylation induced by both LPS and high glucose treatment in peritoneal macrophages.

The effects of AMPK activation on inflammatory cytokines expression were explored in cultured primary peritoneal macrophages. As shown in Fig. 5B, the mRNA levels of TNF- $\alpha$, IL-1 $\beta$, IL- 6 and MCP- 1 were significantly higher in peritoneal macrophages treated with both high glucose and LPS than that treated only with LPS. Interestingly, AICAR pretreatment markedly attenuated these effects. In addition, the levels of TNF- $\alpha$, IL-1 $\beta$, IL- 6 and MCP-1 were significantly higher in the supernatant of peritoneal macrophages treated with both high glucose and LPS than that treated only with LPS. Interestingly, AICAR pretreatment markedly prevented the increase in the levels of inflammatory cytokines described above as shown in Fig. 5C. These data indicated that AMPK activation significantly inhibited inflammatory response in macrophages under the high glucose condition. 


\section{Cellular Physiology Cell Physiol Biochem 2017;42:761-779 and Biochemistry Published online: June 19, $2017 \quad \begin{aligned} & \text { DO 2017 The Author(s). Published by S. Karger AG, Basel } \\ & \text { www.karger.com/cpb }\end{aligned}$ \\ Yang et al.: LKB1/AMPK Signaling Pathway Activation Improved the Survival of Sepsis in Diabetic Mice}

To further explore the mechanism by which AMPK activation protected against LPS induced inflammatory response in high glucose condition, NF- $\mathrm{KB}$ related signaling

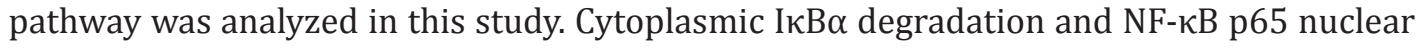
translocation were assessed by immunoblots $1 \mathrm{~h}$ after LPS treatment. As shown in Fig. 5D, compared with the HG group and NG + LPS group, the protein expression level of cytoplasmic I $\kappa \mathrm{B} \alpha$ was significantly lower in the HG + LPS group, which was partly inhibited by AICAR pretreatment. Moreover, the p65 nuclear translocation was significantly enhanced in HG + LPS group compared with that in the HG or NG + LPS groups and this tendency was also partly reversed by AICAR treatment. Previous data indicated that LPS stimulation in macrophages led to the activation of down-stream signal transduction pathways involving NF- $\kappa B$ and MAPKs pathways, thereby resulting in the production of various inflammatory mediators $[25,26]$. P38 phosphorylation was determined in this experiment. As shown in Fig. 5E, both LPS and HG treatment markedly upregulated phosphor-p38 expression and AICAR pretreatment partly prevented the increase in phosphor-p38 expression induced by both LPS and HG stimulation. These data indicated that AMPK activation attenuated the inflammatory responses induced by both LPS and HG treatment in primary peritoneal macrophages at least in part through suppressing p38MAPK and NF- $\kappa B$ signaling pathway.

Both high glucose and LPS-induced LKB1 reduction was mediated by oxidative stress in primary peritoneal macrophages

Liver kinase B1 (LKB1, also known as STK11), originally identified as one of the upstream kinases for AMPK, exhibits an important role in energy metabolism, mainly via association with AMPK [27]. To investigate the role of LKB1 involved in diabetic sepsis, LKB1 expression was examined in macrophages treated with both LPS and HG. As shown in Fig. 6B, a significant decrease in LKB1 and AMPK phosphorylation was observed in peritoneal macrophages after $24 \mathrm{~h}$ incubation in high glucose conditions. Furthermore, LPS stimulation caused a marked decrease in LKB1 and AMPK phosphorylation in a high glucose environment. Interestingly, Ad-LKB1 overexpression resulted in enhanced LKB1 expression and phosphorylation of AMPK in HG + LPS group, which indicated that LKB1 acted as upstream of AMPK in diabetic sepsis. In addition, NAC $(1 \mathrm{mM})$ administration markedly reversed the decrease in LKB1 and phosphor-AMPK expression induced by both LPS and HG treatment, which demonstrated that oxidative stress was involved in the regulation of phosphor-AMPK expression in macrophages treated with both LPS and HG as shown in Fig 6A. HG and LPS co-stimulation significantly increased oxidative stress characterized by increased lipid peroxidation indicator 4-HNE (Fig. 6C).

Given that 4-HNE can inhibit LKB1 expression [28], and HG, LPS treatment significantly increased 4-HNE levels (Fig. 6C), we examined the effects of 4-HNE on LKB1 by immunoprecipitation. 4-HNE-LKB1 adducts were significantly increased in the HG, LPS group compared with that in the HG or NG, LPS groups, which indicated that both HG and LPS induced an additive effect on 4-HNE levels. Interestingly, it was further confirmed that the decrease in LKB1 and phosphorylation of AMPK level was induced by oxidative stress (Fig. 6D). These data indicate that oxidative stress induced by both HG and LPS stimulation attenuated LKB1-AMPK axis in peritoneal macrophages.

AMPK activation inhibited HUVECs permeability induced by both high glucose and LPS stimulation.

We next determined the effects of AMPK activation on LPS-induced disruption of endothelial barrier function in cultured HUVECs under HG conditions. LPS or high glucose induced the decrease in AMPK phosphorylation and its downstream kinase, acetyl coenzyme A carboxylase (ACC) at Ser79 in HUVECs as shown in Fig. 7A. Moreover, both high glucose and LPS treatment further decreased the levels of AMPK and ACC phosphorylation. Furthermore, LPS stimulation caused a marked decrease in LKB1 and AMPK phosphorylation in HUVECs in a high glucose environment (Fig. 7B). Interestingly, Ad-LKB1 overexpression resulted in enhanced LKB1, p-AMPK and p-ACC expression in HG + LPS group as shown 
Yang et al.: LKB1/AMPK Signaling Pathway Activation Improved the Survival of Sepsis in Diabetic Mice

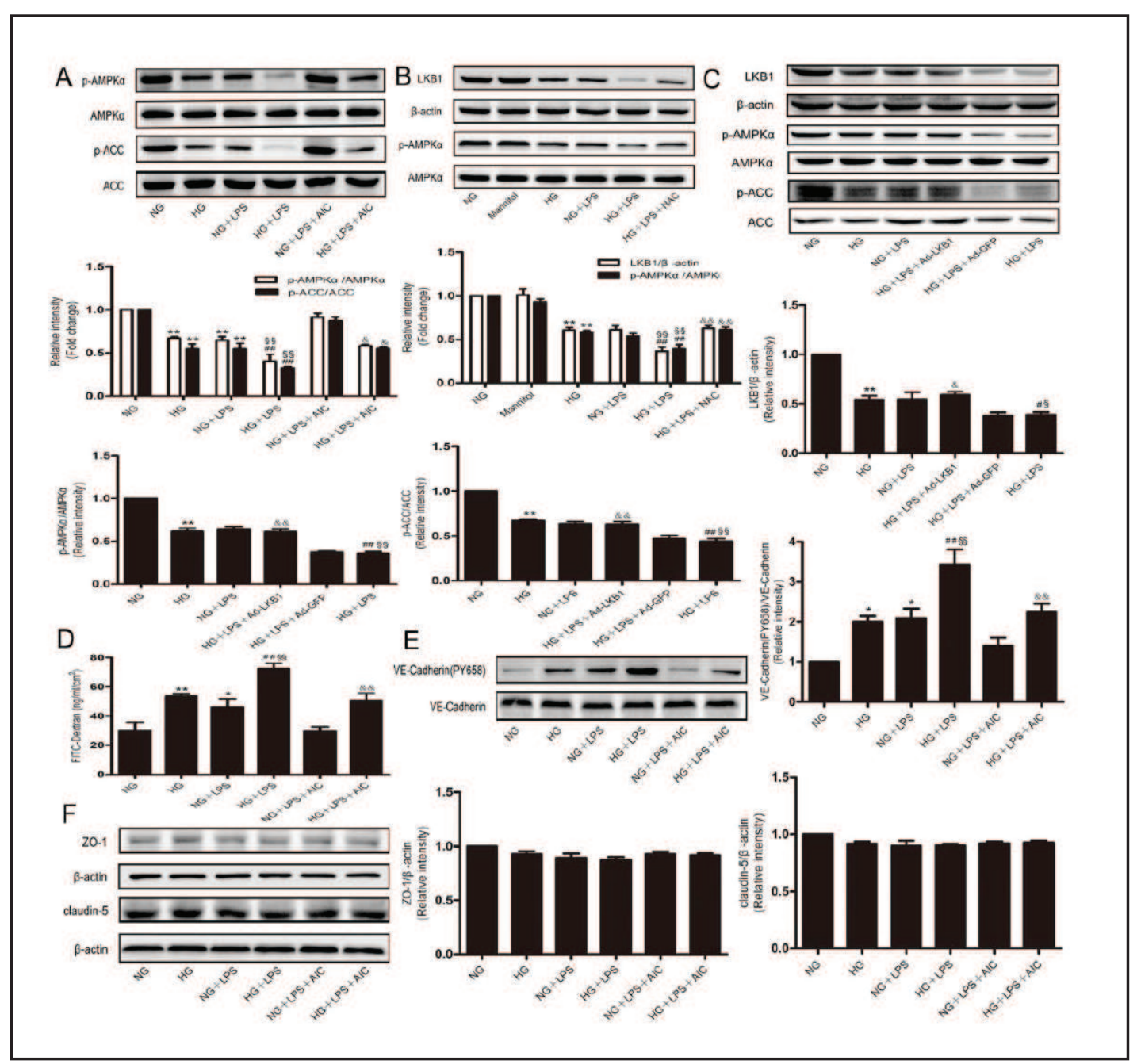

Fig. 7. AMPK stimulation repairs disruption of the HUVEC barrier induced by high glucose combined with lipopolysaccharide (LPS). (A) Representative immunoblots and quantitation of p-AMPK $\alpha$ and p-ACC expression. (B) LKB1, p-AMPK $\alpha, A M P K \alpha$, and $\beta$-actin expression was assessed by immunoblotting and densitometry analysis. (C) LKB1 overexpression activates AMPK signaling. Immunoblot analysis for LKB1, phosphorylated-AMPK $\alpha$ at Thr-172, total AMPK $\alpha$, phosphorylated-ACC at Ser79 and total ACC was shown. HUVECs were infected with Ad-GFP or Ad-LKB1 for $24 \mathrm{~h}$ before shift to HG with or without LPS administration. (D) The translocation of FITC-dextran $(40 \mathrm{kDa})$ from the apical to the basolateral chamber was performed, as described in Materials and Methods. Results are expressed as mean \pm SEM marker transport of 3 independent experiments, each performed in triplicate. (E) Representative immunoblots and quantitation of VE-cadherin phosphorylation at Tyr658. (F) Representative immunoblots and quantitation of ZO-1 and claudin-5. Data are shown as mean \pm SEM from three independent experiments. ${ }^{* *} P<0.01, * P<0.05$ vs NG; ${ }^{\#} P<0.05$, ${ }^{\# \#} P<0.01$ vs NG + LPS; ${ }^{\S} P<0.01,{ }^{\S} P<0.05$ vs HG; ${ }^{\circledR} P<0.05$, ${ }^{\& \&} P<0.01$ vs HG + LPS; ${ }^{\& \&} P<0.01$ vs $\mathrm{HG}+\mathrm{LPS}+$ Ad-GFP. The statistical analysis was from the two-way ANOVA.

in Fig. 7C, and which indicated that LKB1 acted as upstream of AMPK in diabetic sepsis. In addition, NAC administration markedly reversed the decrease in LKB1 and phosphor-AMPK expression induced by both LPS and HG treatment, which demonstrated that oxidative stress was involved in the regulation of phosphor-AMPK expression in HUVECs treated with both LPS and HG as shown in Fig 7B. The effect of AMPK activation on the permeability of HUVECs monolayers was displayed in Fig. 7D. HG alone or NG + LPS mildly increased permeability. Interestingly, HG + LPS dramatically increased permeability in what appeared to be a synergistic effect. AICAR pretreatment significantly abolished these effects.

\section{KARGER}




\section{Cellular Physiology Cell Physiol Biochem 2017;42:761-779

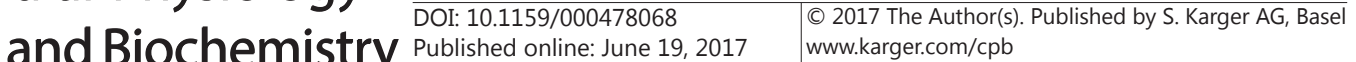 \\ Yang et al.: LKB1/AMPK Signaling Pathway Activation Improved the Survival of Sepsis in Diabetic Mice}

Tyr phosphorylated VE-cadherin acts as a signaling hub to regulate endothelial barrier function by recruiting multiple signaling molecules [29]. Compared with the NG + LPS group, phosphorylation level of VE-cadherin at Tyr658 was significantly higher in the HG + LPS group. However, AICAR pretreatment attenuated these effects as shown in Fig. 7E. Furthermore, the expression of ZO-1 and Claudin-5, proteins markers of tight junction was also determined, and their expression remained unchanged (Fig. 7F). These data indicate that AMPK activation alleviated HUVECs monolayers permeability induced by both LPS and HG treatment via suppression of VE-cadherin phosphorylation.

\section{Discussion}

The current study demonstrated that LKB1/AMPK signaling pathway activation improved the survival of sepsis in diabetic mice, which was associated with decreased lung vascular hyperpermeability and inflammatory response. In details, LKB1/AMPK pathway was inactivated via increased oxidative stress in diabetic sepsis condition. Furthermore, AMPK activation significantly diminished the production of proinflammatory cytokines at transcriptional and post-transcriptional level in primary peritoneal macrophages stimulated by both high glucose and LPS through suppressing NF- $\mathrm{kB}$ and p38MAPK signaling pathways. In addition, AMPK activation also alleviated HUVECs monolayers permeability induced by both high glucose and LPS stimulation via suppression of VE-cadherin phosphorylation. Thus, LKB1/AMPK signaling pathway may serve as a potentially useful therapeutic target for severe infection in diabetic patients.

Clinical evidence regarding infection susceptibility and outcomes revealed that diabetic patients have increased predisposition to infection and a higher mortality rate, which appears to be due to a combination of angiopathy, neuropathy and hyperglycemia $[1,3]$. Previous studies have shown that imbalance between metabolism and the immune system links with inflammatory diseases such as atherosclerosis, obesity, gout, and diabetes $[19,30]$. T1DM-induced alterations in the innate and adaptive components of the immune system play a critical role in the accelerated development of cardiovascular disease and other complications of diabetes, such as enhanced susceptibility to systemic (sepsis) and local infection [31]. Signaling protein that stands out as candidate linking nutrient metabolism and inflammation is the nutrient sensors: AMPK. Moreover, tissue AMPK activity is diminished in obesity, type 2 diabetes and metabolic syndrome. Furthermore, both high glucose and IGF-I suppress AMPK T172 phosphorylation in VSMC [32]. Our data indicate that AMPK is a negative regulator of innate immunity, and serves as an important energy regulator linking energy homeostasis to the regulation of inflammatory signaling.

A few studies have shown that activation of AMPK prevents LPS-induced expression of pro-inflammatory cytokines and suppresses NF- $\kappa B$ and phosphorylation of MAPKs signaling in several cell types [16,33]. Wang et al. [19] reported that pharmacological activation of AMPK by A-769662 inhibited NLRP3 inflammasome activation and IL-1 $\beta$ maturation in macrophages in response to MSU crystals. However, the role of AMPK in diabetes mellitus and septic shock remains poorly defined. To address the role of AMPK, mice rendered diabetic by low-dose STZ administration were used for a better understanding of the enhanced susceptibility to infection, and in particular, in those involved in the pathogenesis of sepsis. In this study, AMPK activation improved survival rate by attenuating cytokines expression and LPS-induced lung vascular leakage in STZ-treated mice after LPS administration. Macrophages from diabetic mice exhibited hyperactivation of NF- $\kappa B$ and p38MAPK in response to LPS stimulation. Importantly, increased NF- $\kappa B$ and p38MAPK activation resulted in increased secretion of TNF- $\alpha$, IL-1 $\beta$, IL- 6 and MCP-1. AMPK activation could alleviate the inflammatory responses in both LPS and high glucose stimulation. These data indicated that AMPK activation improved survival of diabetic mice in septic condition partly due to decreased systemic inflammatory response. 


\section{Cellular Physiology Cell Physiol Biochem 2017;42:761-779 and Biochemistry Published online: June 19, $2017 \quad \begin{aligned} & \text { D 2017 The Author(s). Published by S. Karger AG, Basel } \\ & \text { www.karger.com/cpb }\end{aligned}$ \\ Yang et al.: LKB1/AMPK Signaling Pathway Activation Improved the Survival of Sepsis in Diabetic Mice}

Permeability edema represents a life-threatening complication of acute lung injury and acute respiratory distress syndrome during sepsis, characterized by a combined dysregulation of pulmonary endothelial barrier integrity and alveolar liquid clearance capacity [9]. Castanares-Zapatero et al. [34] showed that $A M P K \alpha_{1}$ counteracted cardiac vascular hyperpermeability and exerted a protective effect against myocardial edema induced by endotoxemia through controlling endothelial tight junctions and maintaining endothelial barrier integrity in septic hearts. However, the role of AMPK is not restricted to tight junction preservation as it has been described in pulmonary microvascular endothelial repair [35]. In addition, Xing and colleagues [36] suggest that protective effects of AMPK against LPS-induced lung dysfunction are mediated by lung vascular endothelium and controlled by Rac GTPase effector PAK1 and tyrosine phosphorylation of VE-cadherin. In this study, we identified the effects of AMPK on endothelial barrier function and vascular permeability by both high glucose and LPS stimulation. As expected, AMPK activation could represent therapeutically promising molecules, since it attenuated transcription factors involved in the activation of pro-inflammatory cytokines and chemokines, all of which are implicated in acute lung injury. In the present study, apart from inducing a potent inhibition of inflammation upon interfering with NF- $\kappa B$ and p38MAPK activation, AICAR was shown to decrease VE-cadherin phosphorylation at Tyr658, a key regulatory site of endothelial barrier function [29], prevent and restore endothelial barrier integrity, resulting in improved survival and lung function during sepsis. Previous studies have shown that AMPK-induced Rac/Cdc42 activation leads to activation of the Rac downstream target PAK, which plays an important role in cell motility, cytoskeletal remodeling, cell constraction and barrier regulation $[36,37]$. However, whether AMPK has effects on these signaling molecules still needs to be further clarified.

Hyperglycemia reduces the levels of superoxide dismutase (SOD), a key antioxidative enzyme. Furthermore, it also increases lipid peroxidation and free radicals such as nitric oxide (NO) [38]. LPS induced ROS production in multiple cell types, and the mechanism included LPS-stimulated mitochondrial fission and reduced PPAR $\gamma$ expression $[39,40]$. Herein, we showed that both high glucose and LPS administration induced extremely high level of ROS production. ROS and other chemical entities could result in the development of oxidative stress, which contributes to various complications associated with diabetes $[41,42]$. LKB1 plays important roles in various biologic responses through regulation of multiple downstream kinases. Recent studies revealed that LKB1 efficiently phosphorylates the catalytic $\alpha$-subunit of AMPK at Thr172 on binding with Ste20-related adaptor protein (STRAD) and mouse protein 25 (MO25), regulatory proteins of LKB1, and that numerous of LKB1-induced biologic responses are mediated through an AMPK-dependent manner $[27,43]$. Oxidation of membrane lipids can lead to the production of reactive aldehydes. Previous evidence has demonstrated that the electrophilic aldehyde lipid peroxidation byproduct 4-hydroxy-2-nonenal (HNE) has the ability to modify and suppress LKB1 activity in the human breast cancer cell line MCF-7 [44, 45]. Oxidative stress and lipid peroxidation products such as HNE are elevated in the failing myocardium of human patients and may contribute to hypertrophic growth in cardiac myocytes. HNE plays an integral role in the promotion of left ventricular hypertrophy in certain pathological conditions [28, 46, 47]. In this study, both high glucose with LPS treatment increased the levels of HNE-protein adducts in macrophages, elevated HNE-LKB1 adduct formation, and significantly diminished the activation of LKB1/AMPK signaling pathway, thereby promoting proinflammatory cytokines secretion. However, similar changes did not exist in HUVECs. These data indicated that oxidative stress was involved in the regulation of LKB1/AMPK signaling pathway.

TNF- $\alpha$, on binding to its specific cell surface receptor, leads to caspase- 8 activation, endothelial cell barrier dysfunction, and paracellular permeability increase [48]. IL-1 $\beta$, whether administered systemically or locally into the pulmonary parenchyma, can acutely increase pulmonary substance P (SP) and vascular permeability, possibly via stimulating PCFs [49]. Gurkan et al. [50] reported that genetic deletion of IL-6 significantly attenuated alveolar-capillary barrier disruption in a two-hit model of acute lung injury. In this study, 


\section{Cellular Physiology Cell Physiol Biochem 2017;42:761-779 \\ \begin{tabular}{l|l} 
and Biochemistry $10.1159 / 000478068$ \\
Published onlne: June 19, 2017 & $\begin{array}{l}\text { @ } 2017 \text { The Author(s). Published by S. Karger AG, Basel } \\
\text { www.karger.com/cpb }\end{array}$ \\
\hline
\end{tabular} \\ Yang et al.: LKB1/AMPK Signaling Pathway Activation Improved the Survival of Sepsis in Diabetic Mice}

AMPK activation protected against lung barrier dysfunction induced by both high glucose and LPS stimulation. Furthermore, AMPK activation was associated with decreased TNF- $\alpha$, IL-1 $\beta$ and IL- 6 levels, which might also have a beneficial effect on improving the vascular permeability basing on the previous studies.

However, in this study, metformin did not lower blood glucose levels when administered to diabetic mice in the in vivo study. Previous study indicated that metformin $(300 \mathrm{mg} / \mathrm{kg} / \mathrm{d})$ attenuated the development of atherosclerosis by reducing mitochondrial fission in an AMPK-dependent manner, but there was no difference in metabolic parameters, including serum lipid and glucose metabolism, between diabetic mice treated with and without metformin [51]. It is speculated that LPS elicited a strong release of inflammatory cytokines which had been shown to impair insulin-mediated glucose disposal [52]. This may account for part of why metformin did not lower blood glucose levels in endotoxemia mice in this study, but it remained to be further elucidated.

In conclusion, our data demonstrated that the AMPK signaling pathway in macrophages and HUVECs, possibly via the AMPK $\alpha 1$ isoform, is down-regulated by LPS synergized with high glucose treatment. This study provides evidence accounting for the mechanisms of the high mortality of sepsis in hosts with diabetes mellitus by demonstrating a dysregulation of cytokine networks and endothelial barrier dysfunction partly due to the suppression of LKB1/AMPK axis. AMPK activation may serve as a potentially useful therapeutic strategy for treating severe infection in diabetic patients. This study also provides a new dimension of metformin in treating diabetes mellitus complicated with sepsis.

\section{Abbreviations}

LKB1 (Liver Kinase B1); AMPK (adenosine monophosphate-activated protein kinase); STZ (streptozotocin); HUVEC (human umbilical vein endothelial cell); LPS (lipopolysaccharide); SIRS (systemic inflammatory response syndrome); ACC (acetyl coenzymecAvcarboxylase);eZO-1g(zonaoccludens-1);44-HNEr(4-hydroxynonenal);1AICAR (5-Aminoimidazole-4-carboxamide1- $\beta$-D-ribofuranoside); Met (metformin); NG (normal glucose); HG (high glucose); NAC (N-Acetyl-L-cysteine); T1DM (type 1 diabetes mellitus).

\section{Acknowledgements}

This study was partly supported by grants from the National Natural Science Foundation of China (No. 81471021, 81170111) and WJ2015MB006.

\section{Disclosure Statement}

The authors have no conflict of interests to declare.

\section{References}

1 Schuetz P, Castro P, Shapiro NI: Diabetes and sepsis: preclinical findings and clinical relevance. Diabetes Care 2011;34:771-778.

-2 Joshi N, Caputo GM, Weitekamp MR, Karchmer AW: Infections in patients with diabetes mellitus. N Engl J Med 1999;341:1906-1912.

-3 Puliti M, Bistoni F, Orefici G, Tissi L: Exacerbation of group B streptococcal sepsis and arthritis in diabetic mice. Microbes Infect 2006;8:2376-2383.

4 Martens GW, Arikan MC, Lee J, Ren F, Greiner D, Kornfeld H: Tuberculosis susceptibility of diabetic mice. Am J Respir Cell Mol Biol 2007;37:518-524.

-5 Parrillo JE: Pathogenetic mechanisms of septic shock. N Engl J Med 1993;328:1471-1477. 


\section{Cellular Physiology Cell Physiol Biochem 2017;42:761-779 \begin{tabular}{c|c|c|c|}
\cline { 2 - 2 } DOI: 10.1159/000478068 & (C) 2017 The Author(s). Published by S. Karger AG, Basel
\end{tabular} and Biochemistry

\begin{tabular}{l|l}
\hline OOI: 10.1159/000478068 & (c) 2017 The Author(s). Published by S. Karger AG, Basel
\end{tabular}

Yang et al.: LKB1/AMPK Signaling Pathway Activation Improved the Survival of Sepsis in Diabetic Mice

6 Gondorf F, Berbudi A, Buerfent BC, Ajendra J, Bloemker D, Specht S, Schmidt D, Neumann AL, Layland LE, Hoerauf A, Hübner MP: Chronic filarial infection provides protection against bacterial sepsis by functionally reprogramming macrophages. PLoS Pathog 2015;11:e1004616.

7 Cohen J: The immunopathogenesis of sepsis. Nature 2002;420:885-891.

-8 Jackson SK, Abate W, Parton J, Jones S, Harwood JL: Lysophospholipid metabolism facilitates Toll-like receptor 4 membrane translocation to regulate the inflammatory response. J Leukoc Biol 2008;84:86-92.

-9 Lucas R, Verin AD, Black SM, Catravas JD: Regulators of endothelial and epithelial barrier integrity and function in acute lung injury. Biochem Pharmacol 2009;77:1763-1772.

10 Yang Z, Kahn BB, Shi H, Xue BZ: Macrophage alpha1 AMP-activated protein kinase (alpha1AMPK) antagonizes fatty acid-induced inflammation through SIRT1. J Biol Chem 2010;285:19051-19059.

11 Ye J, Keller JN: Regulation of energy metabolism by inflammation: a feedback response in obesity and calorie restriction. Aging (Albany NY) 2010;2:361-368.

12 Huang MQ, Zhou CJ, Zhang YP, Zhang XQ Xu W, Lin J, Wang PJ: Salvianolic acid B ameliorates hyperglycemia and dyslipidemia in db/db mice through the AMPK pathway. Cell Physiol Biochem 2016;40:933-943.

13 Qiang G, Yang X, Shi L, Zhang H, Chen B, Zhao Y, Zu M, Zhou D, Guo J, Yang H, Zhang L, Du G: Antidiabetic effect of salvianolic acid A on diabetic animal models via AMPK activation and mitochondrial regulation. Cell Physiol Biochem 2015;36:395-408.

-14 Hu JP, Nishishita K, Sakai E, Yoshida H, Kato Y, Tsukuba T, Okamoto K: Berberine inhibits RANKL-induced osteoclast formation and survival through suppressing the NF-kappaB and Akt pathways. Eur J Pharmacol 2008;580:70-79.

-15 Peairs A, Radjavi A, Davis S, Li L, Ahmed A, Giri S, Reilly CM: Activation of AMPK inhibits inflammation in MRL/lpr mouse mesangial cells. Clin Exp Immunol 2009;156:542-551.

16 Jeong HW, Hsu KC, Lee JW, Ham M, Huh JY, Shin HJ, Kim WS, Kim JB: Berberine suppresses proinflammatory responses through AMPK activation in macrophages. Am J Physiol Endocrinol Metab 2009;296:E955-E964.

17 Hattori Y, Suzuki K, Hattori S, Kasai K: Metformin inhibits cytokine-induced nuclear factor kappaB activation via AMP-activated protein kinase activation in vascular endothelial cells. Hypertension 2006;47:1183-1188.

18 Nath N, Khan M, Paintlia MK, Singh I, Hoda MN, Giri S: Metformin attenuated the autoimmune disease of the central nervous system in animal models of multiple sclerosis. J Immunol 2009;182:8005-8014.

19 Wang Y, Viollet B, Terkeltaub R, Liu-Bryan R: AMP-activated protein kinase suppresses urate crystalinduced inflammation and transduces colchicine effects in macrophages. Ann Rheum Dis 2016;75:286-294.

20 Moitra J, Sammani S, Garcia JG: Re-evaluation of Evans Blue dye as a marker of albumin clearance in murine models of acute lung injury. Transl Res 2007;150:253-265.

21 Kim MJ, Nepal S, Lee ES, Jeong TC, Kim SH, Park PH: Ethanol increases matrix metalloproteinase-12 expression via NADPH oxidase-dependent ROS production in macrophages. Toxicol Appl Pharmacol 2013;273:77-89.

22 Miyake S, Makimura M, Kanegae Y, Harada S, Sato Y, Takamori K, Tokuda C, Saito I: Efficient generation of recombinant adenoviruses using adenovirus DNA-terminal protein complex and a cosmid bearing the fulllength virus genome. Proc Natl Acad Sci USA 1996;93:1320-1324.

23 Zhao C, Wang P, Xiao X, Chao J, Chao L, Wang DW, Zeldin DC: Gene therapy with human tissue kallikrein reduces hypertension and hyperinsulinemia in fructose-induced hypertensive rats. Hypertension 2003;42:1026-1033.

24 Xie Z, Dong Y, Scholz R, Neumann D, Zou MH: Phosphorylation of LKB1 at serine 428 by protein kinase $\mathrm{C}$-zeta is required for metformin-enhanced activation of the AMP-activated protein kinase in endothelial cells. Circulation 2008;117:952-962.

25 Guha M, Mackman N: LPS induction of gene expression in human monocytes. Cell Signal 2001;13:85-94.

26 Li Q, Verma IM: NF-kappaB regulation in the immune system. Nat Rev Immunol 2002;2:725-734.

27 Shaw RJ, Kosmatka M, Bardeesy N, Hurley RL, Witters LA, Depinho RA, Cantley LC: The tumor suppressor LKB1 kinase directly activates AMP-activated kinase and regulates apoptosis in response to energy stress. Proc Natl Acad Sci USA 2004;101:3329-3335.

28 Dolinsky VW, Chan AY, Robillard Frayne I, Light PE, Des Rosiers C, Dyck JR: Resveratrol prevents the prohypertrophic effects of oxidative stress on LKB1. Circulation 2009;119:1643-1652. 


\section{Cellular Physiology Cell Physiol Biochem 2017;42:761-779 \begin{tabular}{l|l} 
DOI: 10.1159/000478068 & $\begin{array}{l}\text { @ 2017 The Author(s). Published by S. Karger AG, Basel } \\
\text { www.karger.com/cpb }\end{array}$ \\
\hline
\end{tabular}}

Yang et al.: LKB1/AMPK Signaling Pathway Activation Improved the Survival of Sepsis in Diabetic Mice

29 Cain RJ, Vanhaesebroeck B, Ridley AJ: The PI3K p110alpha isoform regulates endothelial adherens junctions via Pyk2 and Rac1. J Cell Biol 2010;188:863-876.

-30 McQueen FM, Chhana A, Dalbeth N: Mechanisms of joint damage in gout: evidence from cellular and imaging studies. Nat Rev Rheumatol 2012;8:173-181.

- 31 Filgueiras LR, Brandt SL, Wang S, Wang Z, Morris DL, Evans-Molina C, Mirmira RG, Jancar S, Serezani CH: Leukotriene B4-mediated sterile inflammation promotes susceptibility to sepsis in a mouse model of type 1 diabetes. Sci Signal 2015;8:ra10.

-32 Ning J, Xi G, Clemmons DR: Suppression of AMPK activation via S485 phosphorylation by IGF-I during hyperglycemia is mediated by AKT activation in vascular smooth muscle cells. Endocrinology 2011;152:3143-3154.

-33 Sag D, Carling D, Stout RD, Suttles J: Adenosine 5'-monophosphate-activated protein kinase promotes macrophage polarization to an anti-inflammatory functional phenotype. J Immunol 2008;181:8633-8641.

-34 Castanares-Zapatero D, Bouleti C, Sommereyns C, Gerber B, Lecut C, Mathivet T, Horckmans M, Communi D, Foretz M, Vanoverschelde JL, Germain S, Bertrand L, Laterre PF, Oury C, Viollet B, Horman S, Beauloye C: Connection between cardiac vascular permeability, myocardial edema, and inflammation during sepsis: role of the alpha1AMP-activated protein kinase isoform. Crit Care Med 2013;41:e411-e422.

-35 Creighton J, Jian MY, Sayner S, Alexeyev M, Insel PA: Adenosine monophosphate-activated kinase alpha1 promotes endothelial barrier repair. FASEB J 2011;25:3356-3365.

-36 Xing J, Wang Q Coughlan K, Viollet B, Moriasi C, Zou MH: Inhibition of AMP-activated protein kinase accentuates lipopolysaccharide-induced lung endothelial barrier dysfunction and lung injury in vivo. Am J Pathol 2013;182:1021-1030.

- 37 Birukova AA, Xing J, Fu P, Yakubov B, Dubrovskyi O, Fortune JA, Klibanov AM, Birukov KG: Atrial natriuretic peptide attenuates LPS-induced lung vascular leak: role of PAK1. Am J Physiol Lung Cell Mol Physiol 2010;299:L652-L663.

- 38 Pitocco D, Zaccardi F, Di Stasio E, Romitelli F, Santini SA, Zuppi C, Ghirlanda G: Oxidative stress, nitric oxide, and diabetes. Rev Diabet Stud 2010;7:15-25.

- 39 Park J, Min JS, Kim B, Chae UB, Yun JW, Choi MS, Kong IK, Chang KT, Lee DS: Mitochondrial RoS govern the LPS-induced pro-inflammatory response in microglia cells by regulating MAPK and NF-kappaB pathways. Neurosci Lett 2015;584:191-196.

-40 de Souza LF, Barreto F, da Silva EG, Andrades ME, Guimarães EL, Behr GA, Moreira JC, Bernard EA: Regulation of LPS stimulated ROS production in peritoneal macrophages from alloxan-induced diabetic rats: involvement of high glucose and PPARgamma. Life Sci 2007;81:153-159.

-41 Russell JW, Berent-Spillson A, Vincent AM, Freimann CL, Sullivan KA, Feldman EL: Oxidative injury and neuropathy in diabetes and impaired glucose tolerance. Neurobiol Dis 2008;30:420-429.

-42 Huynh K, Kiriazis H, Du XJ, Love JE, Jandeleit-Dahm KA, Forbes JM, McMullen JR, Ritchie RH: Coenzyme Q10 attenuates diastolic dysfunction, cardiomyocyte hypertrophy and cardiac fibrosis in the $\mathrm{db} / \mathrm{db}$ mouse model of type 2 diabetes. Diabetologia 2012;55:1544-1553.

43 Shackelford DB, Shaw RJ: The LKB1-AMPK pathway: metabolism and growth control in tumour suppression. Nat Rev Cancer 2009;9:563-575.

44 Schneider C, Porter NA, Brash AR: Routes to 4-hydroxynonenal: fundamental issues in the mechanisms of lipid peroxidation. J Biol Chem 2008;283:15539-15543.

-45 Wagner TM, Mullally JE, Fitzpatrick FA: Reactive lipid species from cyclooxygenase-2 inactivate tumor suppressor LKB1/STK11: cyclopentenone prostaglandins and 4-hydroxy-2-nonenal covalently modify and inhibit the AMP-kinase kinase that modulates cellular energy homeostasis and protein translation. J Biol Chem 2006;281:2598-2604.

-46 Nakamura K, Kusano K, Nakamura Y, Kakishita M, Ohta K, Nagase S, Yamamoto M, Miyaji K, Saito H, Morita H, Emori T, Matsubara H, Toyokuni S, Ohe T: Carvedilol decreases elevated oxidative stress in human failing myocardium. Circulation 2002;105:2867-2871.

47 Siwik DA, Tzortzis JD, Pimental DR, Chang DL, Pagano PL, Singh K, Sawyer DB, Colucci WS: Inhibition of copper-zinc superoxide dismutase induces cell growth, hypertrophic phenotype, and apoptosis in neonatal rat cardiac myocytes in vitro. Circ Res 1999;85:147-153. 
48 Sawant DA, Tharakan B, Wilson RL, Stagg HW, Hunter FA, Childs EW: Regulation of tumor necrosis factoralpha-induced microvascular endothelial cell hyperpermeability by recombinant B-cell lymphoma-extra large. J Surg Res 2013;184:628-637.

49 Zhuang J, Xu J, Zhang C, Xu F: IL-1 beta acutely increases pulmonary SP and permeability without associated changes in airway resistance and ventilation in anesthetized rats. Respir Physiol Neurobiol 2011;175:1219.

50 Gurkan OU, He C, Zielinski R, Rabb H, King LS, Dodd-o JM, D’Alessio FR, Aggarwal N, Pearse D, Becker PM: Interleukin-6 mediates pulmonary vascular permeability in a two-hit model of ventilator-associated lung injury. Exp Lung Res 2011;37:575-584.

-51 Wang Q Zhang M, Torres G, Wu S, Ouyang C, Xie Z, Zou MH: Metformin suppresses diabetes-accelerated atherosclerosis via the inhibition of Drp1-mediated mitochondrial fission. Diabetes 2017;66:193-205.

- 52 Mulligan KX, Morris RT, Otero YF, Wasserman DH, McGuinness OP: Disassociation of muscle insulin signaling and insulin-stimulated glucose uptake during endotoxemia. PLoS One 2012;7:e30160. 